\title{
Remembering Mary Jeanne Kreek and her many contributions to addiction science
}

W hen Dr. Mary Jeanne Kreek passed away on March 27, at age 84 , the field of addiction science lost a true giant. Her research not only paved the way for the first medication treatment for opioid addiction, but also made landmark contributions to our understanding of addiction as a brain disorder, the genetic factors underlying addictive disorders, and the close links between injection drug use and HIV. Kreek had been the Patrick E. and Beatrice M. Haggerty Professor and Head of the Laboratory of the Biology of Addictive Diseases at The Rockefeller University in New York City and Senior Physician of The Rockefeller University Hospital.

Bitten by the science bug at an early age, Kreek already knew when she was a little girl that she would go into medicine. As she tells it in an oral history interview for The Rockefeller University ${ }^{1}$, she entered her first science fair in the sixth grade, and at age 15 participated in a TV series called Youth Wants to Know. Following a bout of polio in her early teens, she studied and practiced ballet to help recover, and then danced semi-professionally in the National Ballet Company in Washington DC, where she lived. She then taught dance to support herself during her undergraduate education at Wellesley College. After graduating in 1958 , she went on to receive her medical degree from Columbia University College of Physicians \& Surgeons in 1962.

Kreek's initial contributions to addiction medicine started in 1964, while she was in her second year of residency in Internal Medicine at Cornell University-New York Hospital Medical Center. She was invited to join the lab of Vincent Dole at The Rockefeller Institute for Medical Research. Vincent Dole, along with psychiatrist Marie Nyswander, was researching the biology of addiction. Together with Kreek, the researchers determined that heroin addiction involved neurochemical alterations and that the longer-acting orally administered opioid analgesic methadone could potentially be used to help treat it.

The recognition by Kreek and her colleagues that heroin addiction was a disorder of the brain that had behavioral consequences was a major shift in a world where addiction was still considered by most people to be a criminal behavior or a moral

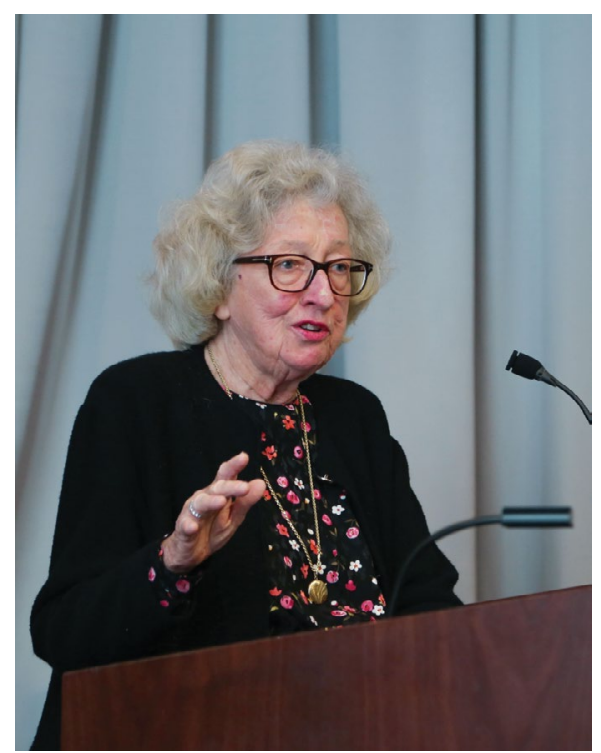

Credit: JOSIE ANDERSON

failing. Working with formerly incarcerated people in active opioid use whom they brought to Rockefeller University Hospital, the research team found that individuals with severe heroin addiction were no longer able to obtain a high (euphoria) from the drug but took it just to feel normal-a crucial distinction that remains central to how we understand addictive behavior today. This was the theme of a landmark paper ${ }^{2}$ Kreek co-wrote with Dole and Nyswander about their research, "Narcotic blockade" in Archives of Internal Medicine in 1966.

Kreek went on to develop techniques to measure methadone concentration in blood and other tissues, which facilitated studies on its efficacy and safety and eventually led to the US Food and Drug Administration (FDA) approval of methadone as a treatment for heroin addiction in 1973. For the next 20 years, until the FDA approved levo-alpha-acetyl-methadol (LAAM) for this indication in 1993, methadone was the only medication available to people with heroin addiction. While LAAM is no longer on the market, methadone is the preferred treatment in many countries for patients with severe addiction, who inject heroin and other opioids and are at highest risk for relapsing, overdosing, and dropping out of treatment. Methadone is included on the
World Health Organization's (WHO) list of the most efficacious, safe, and cost-effective medicines for priority conditions $s^{3}$, and it has helped countless patients with opioid addiction toward leading healthy and productive lives.

In the 1970s, when methadone was first making inroads treating patients with opioid addiction, the mechanisms of opioid compounds' actions in the brain were still poorly understood. Opioid receptors were first identified in 1973, and opioid peptides were discovered in 1975. Kreek's research in her lab at The Rockefeller University over the following years clarified how the endogenous opioid signaling system plays a role not only in opioid addiction but also in addiction to alcohol and cocaine.

Among her many important contributions to the field of addiction research over subsequent decades, Kreek was the first to identify injection drug use as the second major risk behavior (after unprotected sex) for HIV transmission. Kreek also played a role in the development of the opioid partial agonist buprenorphine as an opioid addiction treatment, which was finally approved for that indication in 2002 (and is also on the WHO list of essential medicines). Later she went on to elucidate the genetic underpinnings of addictive disorders, including polymorphisms controlling the expression of mu and kappa opioid receptors, as well as polymorphisms associated with atypical stress responses contributing to vulnerability for drug and alcohol addiction.

Kreek received many honors for her pathbreaking contributions, including the Betty Ford Award from the Association for Multidisciplinary Education and Research in Substance use and Addiction in 1996, the R. Brinkley Smithers Distinguished Scientist Award of the American Society of Addiction Medicine in 1999, and the National Institute on Drug Abuse's Lifetime Science Award in 2014. The College on Problems of Drug Dependence awarded her the Nathan B. Eddy Memorial Award for Lifetime Excellence in Drug Abuse Research in 1999 and the Marian Fischman Lectureship Award in 2005. In 2000, the Doctor Honoris Causa was conferred on her by the University of Uppsala, Sweden.

Kreek's emphasis on addiction as a brain disorder and her discoveries of how brain 
stress responses contribute to addiction were far ahead of their time. But besides her brilliant scientific mind, she also possessed an extraordinary ability to interface with the 'real world' to help translate her research findings to inform policy.

Mary Jeanne's loss is particularly painful to those of us who knew and worked with her because, apart from her scientific contributions, she was also an extraordinary role model and mentor, especially for women scientists. There were no obstacles that would stop her-whether it was undertaking the laborious research necessary to prove a hypothesis, speaking up to support minority scientists, confronting atavistic ways of treating addiction, or even climbing a mountain to enjoy lunch 'with a view' during an International College of Neuropsychopharmacology meeting in Colorado-and her drive was infectious. Her brilliance, alongside her insatiable energy, her sharp sense of mission, and her kindness inspired and transformed many of us in the field.

And importantly, in 2021 as we continue to confront the worst opiod crisis our country has ever experienced, Mary Jeanne's work left us with some of the most powerful tools we have to prevent mortality and achieve recovery.

Nora D. Volkow (D) ${ }^{1 \times}$ and George F. Koob² ${ }^{1}$ National Institute on Drug Abuse, National
Institutes of Health, Bethesda, MD, USA.

${ }^{2}$ National Institute on Alcohol Abuse and Alcoholism, National Institutes of Health, Bethesda, MD, USA.

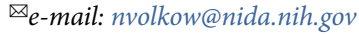

Published online: 14 May 2021

https://doi.org/10.1038/s41593-021-00863-Z

\section{References}

1. Interview with Mary Jeanne Kreek. The Rockefeller University https://www.rockefeller.edu/about/history/oral-history-project/ interview-mary-jeanne-kreek/ (2021).

2. Dole, V. P., Nyswander, M. E. \& Kreek, M. J. Narcotic blockade. Arch. Intern. Med. 118, 304-309 (1966).

3. 21 st WHO Essential Medicines List (EML). WHO Model List of Essential Medicines https://www.who.int/groups/expertcommittee-on-selection-and-use-of-essential-medicines essential-medicines-lists (World Health Organization, 2019). 